\title{
Fast and sensitive method for phosphorus determination in dairy products
}

\author{
Anna Gliszczyńska-Świgło ${ }^{1}\left[\right.$ Iga $^{\text {Rybicka }}{ }^{1}$ (]
}

Received: 12 December 2020 / Revised: 21 April 2021 / Accepted: 10 May 2021 / Published online: 9 June 2021

(c) The Author(s) 2021

\begin{abstract}
The spectrophotometric molybdenum blue method for phosphorus determination was adapted to a multiwell plate format. The method was sensitive and allowed for the simultaneous determination of phosphorus in many samples. It was cheap and eco-friendly due to application of small volumes of reagents and, therefore, it meets the requirements for "green" or sustainable chemistry. The method's limit of detection (LOD) is $0.37 \mu \mathrm{g} / \mathrm{mL}$ and its limit of quantification (LOQ) is $1.13 \mu \mathrm{g} /$ $\mathrm{mL}$. Its linearity is up to $30 \mu \mathrm{g}$ of phosphorus $/ \mathrm{mL}$. The method was applied for the determination of phosphorus in 65 dairy products (yogurts, yogurt drinks, buttermilks, kefirs and homogenized cheeses) of strawberry, peach, forest fruits, vanilla and other flavours. The phosphorus content was $143-226 \mathrm{mg} / 100 \mathrm{~g}$ in flavoured yogurts, $78-204 \mathrm{mg} / 100 \mathrm{~g}$ in yogurt drinks, $89-218 \mathrm{mg} / 100 \mathrm{~g}$ in kefirs, around $195 \mathrm{mg} / 100 \mathrm{~g}$ in buttermilks, and 165-277 mg/100 g in homogenized cheeses. The presented method can be used in the routine quantitative analysis of the total phosphorus content in dairy products.
\end{abstract}

Keywords Phosphorus $\cdot$ Mineral $\cdot$ Molybdenum blue $\cdot$ UV-Vis $\cdot$ Sustainable chemistry $\cdot$ Dairy

\section{Introduction}

Phosphorus $(\mathrm{P})$ is present in various biological, agricultural, environmental, pharmaceutical, and food samples (Vallapragada et al. 2011; Adesanwo et al. 2013). P is an essential nutrient naturally found in most of plant and animal foods. It is primarily responsible for the formation of bones and teeth (Mancini et al. 2018). The Nutrient Reference Value (NRV) for $\mathrm{P}$ is $700 \mathrm{mg} /$ day for adults (European Parliament and Council 2011) but most of the population studies estimate its intake to be 1300-1800 mg/day (Calvo and Uribarri 2013; Mancini et al. 2018). It is not as high as the tolerable upper limit (4000 mg/day) (Institute of Medicine, Food and Nutrition Board 1997) but some authors claim that its content in food products is underestimated and therefore the intake level is also underestimated (Calvo et al. 2013; Borgi 2019). This is especially relevant because $\mathrm{P}$ is also added to food products in a form of different food additives, which have a higher bioavailability than $\mathrm{P}$ from natural sources (Fukagawa

Anna Gliszczyńska-Świgło

anna.gliszczynska-swiglo@ue.poznan.pl

1 Institute of Quality Science, Poznań University of Economics and Business, Al. Niepodległości 10, 61-875 Poznan, Poland et al. 2011). The excess of $P$ intake may significantly disrupt the hormonal regulation of $\mathrm{P}$ contributing to disordered mineral metabolism, vascular calcification, bone loss and impaired kidney function as shown for healthy young adults (Calvo and Uribarri 2013). Other studies also associated a high intake of $\mathrm{P}$ with the increased risk of type 2 diabetes or effects on bone traits (Mancini et al. 2018). Therefore, the level of this element should be monitored in food.

Minerals are mostly determined using atomic spectroscopy, but because of the high LOD for P [e.g. $75 \mathrm{mg} / \mathrm{L}$ for atomic absorption spectroscopy in a flame (F-AAS)] (Perkin-Elmer 2011) another method must be applied for its determination. Several analytical methods have been proposed for the determination of $\mathrm{P}$ in food samples, including UV-Vis spectrophotometric methods (Jastrzębska 2009; Kurzawa et al. 2009), chromatography (Ruiz-Calero and Galceran 2005; Sekiguchi et al. 2000), electrophoresis (Dušek et al. 2003), X-ray fluorescence (Jastrzębska et al. 2003), electrothermal AAS (ETAAS) (Coşkun and Akman 2005), inductively coupled plasma with optical emission spectrometry (ICP-OES) (Hwang et al. 2015), ICP with mass spectrometry (ICP-MS) (Cozzolino et al. 2008), and P-NMR (Cade-Menun 2005). The development of an analytical method usually results in obtaining a more sensitive, faster, simpler, cheaper, more informative or more environmentally 
sustainable method (Bergquist and Turner 2018). Methods that use less toxic or smaller amounts of reagents or solvents additionally meet the requirements of so-called "green" or sustainable chemistry (Koel and Kaljurand 2006). Thus, the aim of this study was to adapt the molybdenum blue method to a 48-microwell plate format. This method is based on the formation of molybdophosphoric acid from orthophosphate and molybdate under acidic conditions followed by reduction to molybdenum blue (Murphy and Riley 1962). The intensity of blue colour is proportional to the amount of $\mathrm{P}$ in solution. In the study, we used a novel approach based on the simultaneous determination of $\mathrm{P}$ in many samples that can be used in a precise and accurate routine analysis of the mineral in dairy products. The proposed method was applied to various dairy samples to provide up-to-date data on $\mathrm{P}$ content in food products.

\section{Materials and methods}

\subsection{Materials}

Randomly selected flavoured dairy products of different brands and producers including yogurts $(n=21)$, yogurt drinks $(n=11)$, kefirs $(n=10)$, buttermilks $(n=5)$ and homogenized cheeses $(n=18)$ were purchased in local shops in Poland in 2018 (Table S1; Supplementary Material). ERM-BD150 Skimmed Milk Powder (European Commission's Joint Research Centre, Geel, Belgium) was selected as certified reference material (CRM) to verify the accuracy of the analytical procedure.

\subsection{Samples preparation}

Heterogeneous products were homogenized using Polytron PT 1300 D (Kinematica AG, Luzern, Switzerland) at $13,500 \mathrm{~g}$ and mineralized using microwave digestion as described by Lesniewicz et al. (2010). The mineralization was conducted in a microwave oven (CEM Corporation Mars 6, Matthews, USA). After cooling, samples were filled to $50 \mathrm{~mL}$ with demineralized water (Hydrolab, Wiślina, Poland). The mineralization of each sample was conducted in triplicates. The blank sample was prepared under the same conditions.

\subsection{Certified reference material's preparation}

The determination of $\mathrm{P}$ in CRM was performed for dried material. For this purpose, the CRM was dried in the oven at $102{ }^{\circ} \mathrm{C} \pm 0.5^{\circ} \mathrm{C}$ until constant mass. Subsequently, the $\mathrm{CRM}$ was mineralized as described in the previous section.

\subsection{Reagent preparation}

The solution of 5\% ammonium molybdate (molybdate-sulfuric [VI] acid) was prepared by mixing $5 \mathrm{~g}$ of anhydrous ammonium molybdate dissolved in $60 \mathrm{~mL}$ of demineralized water with a solution of $15 \mathrm{~mL}$ of concentrated sulphuric acid in $40 \mathrm{~mL}$ of demineralized water. The reagent was stored in an amber bottle at $4{ }^{\circ} \mathrm{C}$. Its stability was confirmed for four weeks.

The solution of $0.5 \%$ hydroquinone (benzene-1,4-diol) was prepared by dissolving $0.5 \mathrm{~g}$ hydroquinone (benzene1,4-diol) in $100 \mathrm{~mL}$ of demineralized water with $10 \mu \mathrm{L}$ of concentrated sulphuric acid. The reagent was stored in an amber bottle at $4{ }^{\circ} \mathrm{C}$. Its stability was confirmed for four weeks.

The solution of $20 \%$ sodium sulphite $\left(\mathrm{Na}_{2} \mathrm{SO}_{3}\right)$ was prepared freshly (daily). P for AAS (1000 mg/L of water; TraceCERT, Supelco, Sigma-Aldrich, Saint Louis, MO, USA) was used as a standard.

\subsection{Spectrophotometric determination of phosphorus}

A 48-microwell plate (flat bottom) (Nunclon Delta Surface, Thermo Fisher Scientific, Roskilde, Demark) was used to determine the content of total $\mathrm{P}$ in mineralized samples. Each well contained $0.08 \mathrm{~mL}$ of a sample and $0.08 \mathrm{~mL}$ of water (or $0.16 \mathrm{~mL}$ of water as a blank), $0.08 \mathrm{~mL}$ of $5 \%$ molybdate-sulfuric (VI) acid solution, $0.08 \mathrm{~mL}$ of $0.5 \%$ hydroquinone (benzene-1,4-diol), and $0.08 \mathrm{~mL}$ of $20 \%$ sodium sulphite. The plate was left for $30 \mathrm{~min}$ in the dark and the absorbance was measured at $823 \mathrm{~nm}$ using BioTek PowerWave XS2 microplate spectrophotometer (Biokom, Warsaw, Poland). Three determinations were performed for each digest of the sample.

Quantification of $\mathrm{P}$ was performed using an external standard method. The six-point calibration curves were prepared with standard solution $(0-30 \mu \mathrm{g}$ of $\mathrm{P} / \mathrm{mL}$ of sample). The LOD and LOQ were calculated from the standard deviations of the blank samples $(n=20)$ and the slopes of the calibration curves $(n=6)$.

\subsection{Statistical analysis}

The data in Fig. 1 and Table S1 (Supplementary Material) were presented as mean \pm SD for each sample. Statistical analyses were carried out using Statistica 13.3 (2017) (StatSoft, Inc., Tulsa, OK, USA). All data were submitted to one-way analysis of variance (ANOVA). The significance of differences between mean values was determined by the least significant differences test (LSD) or Tukey test with 

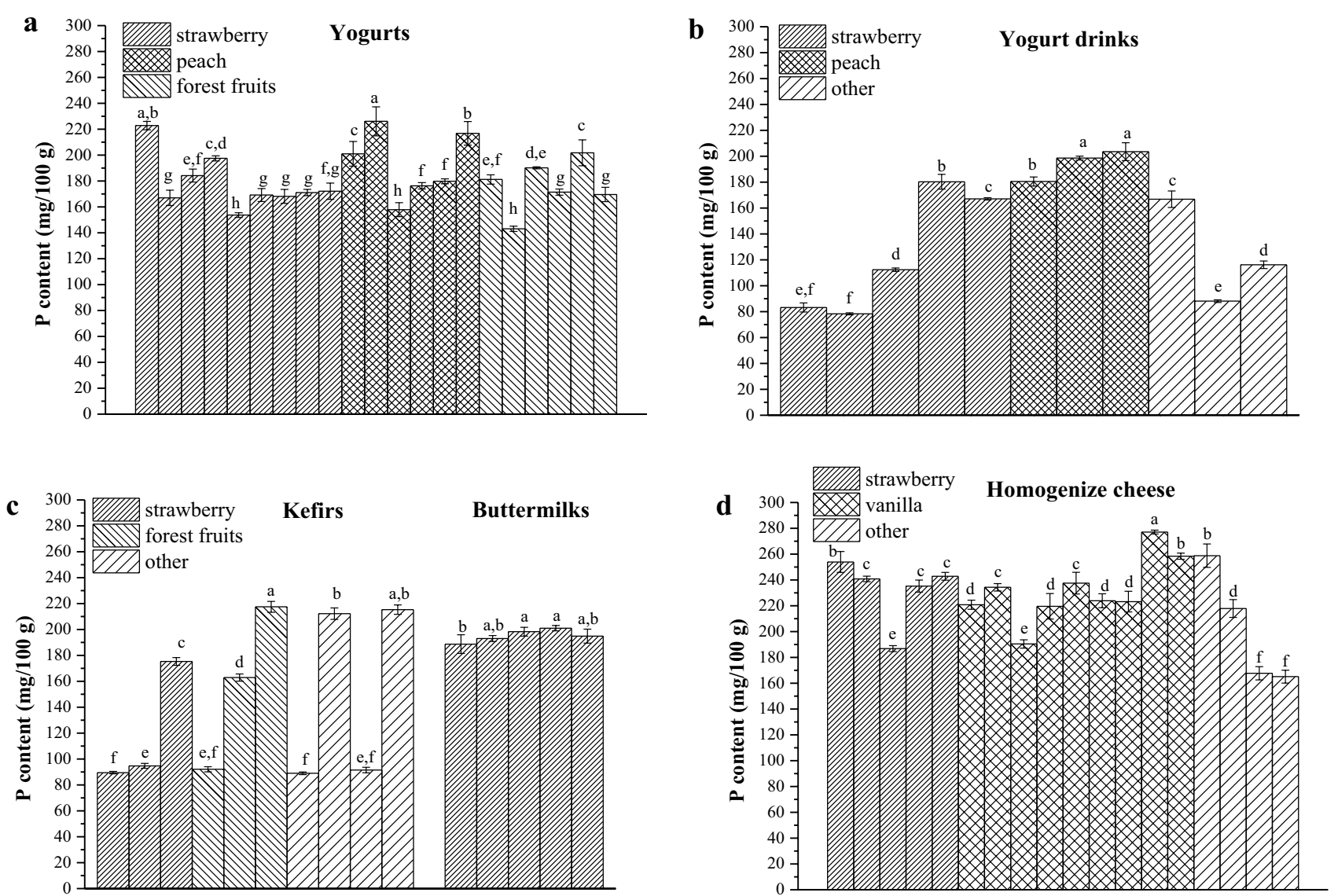

Fig. 1 The comparison of phosphorus content in dairy products of different categories and flavours. Data are presented as mean $\pm \mathrm{SD}$; $\mathbf{a}-$ h: significant differences $(\mathrm{p}<0.05)$ between mean values within the

category of product were indicated by different letters (sorted from the highest to lowest values, where "a" was the highest)

unequal sample size (differences between categories and flavours) at $\alpha=0.05$.

\section{Results and discussion}

\subsection{Method validation and cost}

Analytical characteristics of spectrophotometric molybdenum blue method adapted to a 48-microwell plate included: linearity, precision, accuracy and sensitivity expressed as LOD and LOQ.

Precision of the method was evaluated as the relative standard deviation (RSD) of the intra-day (repeatability, $\mathrm{n}=5$ ) and inter-day (reproducibility in three days, $\mathrm{n}=15$ ) determinations of $\mathrm{P}$ standard solution. The repeatability and reproducibility was not higher than $3.2 \%$ and $4.0 \%$, respectively, indicating satisfactory precision.

Quantification of $\mathrm{P}$ was performed using an external standard method. The calibration curve for $\mathrm{P}(\mathrm{y}=\mathrm{ax}+\mathrm{b})$ was as follows: $\mathrm{a}=0.0326 \pm 0.0005$ and $\mathrm{b}=0.0476 \pm 0.0004$

$(n=6)$ with a very good linearity (average $r=0.999$; $\mathrm{RSD}=0.03 \%$ ) to at least $30 \mu \mathrm{g} / \mathrm{mL}$ (final concentration in the well, absorbance not higher than 1.1). The LOD and the LOQ for P determination were $0.37 \mu \mathrm{g} / \mathrm{mL}$ and $1.13 \mu \mathrm{g} / \mathrm{mL}$ $(9.3 \mathrm{mg} / 100 \mathrm{~g}$ and $27.9 \mathrm{mg} / 100 \mathrm{~g}$ of product), respectively.

The accuracy of the method was confirmed with CRM. The declared content of total P in CRM was $11.0 \pm 0.6 \mathrm{~g}$ in $\mathrm{kg}$ of dried powder, whereas the determined value was $10.9 \pm 0.3 \mathrm{~g} / \mathrm{kg}$.

The method allowed for a precise analysis of a large number of samples at the same run with relatively low cost. The cost of $\mathrm{P}$ determination was calculated for 480 samples taking into account the cost of reagents and plate, and the fact that the same plate can be used at least ten times. The estimated cost of analysis was about $€ 28 / \$ 30$ ( $€ 2.8 / \$ 3.0$ per plate) (November, 20, 2020, Poland).

\subsection{Total phosphorus content in dairy products}

The content of $\mathrm{P}$ in different food products can be found in the literature, e.g. in the US or Polish databases 
(Kunachowicz et al. 2005; USDA 2019), but some authors indicate significant discrepancies between values of analytical determinations and existing databases. Borgi (2019) underlined the limited number of studies conducted for $\mathrm{P}$ content in grocery items and claimed that the data from nutritional databases are underestimated and therefore the data on its intake are also underestimated. Therefore, we applied the presented method for the determination of $\mathrm{P}$ in a range of dairy products. Some of the presented results are a novelty in literature, e.g. the content of $\mathrm{P}$ in flavoured yogurts or drinking dairy products.

The content of $\mathrm{P}$ was determined in 65 dairy products from five categories. Results presented in Fig. 1 and Table S1 (Supplementary Material) show all data separately for each category. The differences between P content in products of different flavours within one category were not statistically significant $(\mathrm{p}>0.05)$. The content of $\mathrm{P}$ in all milk products ranged from 78 to $277 \mathrm{mg}$ in $100 \mathrm{~g}$; the lowest average content was found in yogurt drinks $(143 \pm 48 \mathrm{mg} / 100 \mathrm{~g})$ and kefirs $(144 \pm 58 \mathrm{mg} / 100 \mathrm{~g})$, while the highest in homogenized cheeses $(225 \pm 31 \mathrm{mg} / 100 \mathrm{~g})$. The content of $\mathrm{P}$ in buttermilks $(195 \pm 5 \mathrm{mg} / 100 \mathrm{~g})$ and yogurts $(182 \pm 22 \mathrm{mg} / 100 \mathrm{~g})$ was similar. Statistical analysis revealed significant differences among subcategory of homogenized cheeses and yogurts, yogurt drinks, kefirs $(\mathrm{p}<0.05)$ but no significant differences were found between homogenized cheeses and buttermilks $(\mathrm{p}>0.05)$.

The content of P in yogurts ranged from $143 \mathrm{mg}$ (blueberry) to $225 \mathrm{mg}$ in $100 \mathrm{~g}$ (strawberry and peach). The literature data mostly relate to plain yogurts with the content of $\mathrm{P}$ from $88 \mathrm{mg} / 100 \mathrm{~g}$ (Fuente et al. 2003) to $150-170 \mathrm{mg} / 100 \mathrm{~g}$ (Güler 2007; Zamberlin et al. 2012). The content of P in flavoured yogurts found in databases is higher, around $300 \mathrm{mg} / 100 \mathrm{~g}$, but it is a calculated, not analytically determined, value (USDA 2019). The relatively large discrepancies observed for analytical data and databases confirm the need of a reliable and fast method for $\mathrm{P}$ determination underlined by other authors (Calvo et al. 2013; Borgi 2019).

In the group of yogurt drinks, the lowest content of $\mathrm{P}<85 \mathrm{mg} / 100 \mathrm{~g}$, was found in strawberry yogurts and the highest, $180-200 \mathrm{mg} / 100 \mathrm{~g}$, in strawberry and peach products. From analysed kefirs, the best source of $\mathrm{P}$, delivering $210-220 \mathrm{mg} / 100 \mathrm{~g}$, were three kefirs: peach, forest fruits and vanilla. Five out of ten kefirs contained only 90-95 mg of P in $100 \mathrm{~g}$ (different flavours). The content of $\mathrm{P}$ in buttermilks (all of strawberry flavour) was much higher than in yogurt drinks or kefirs. Buttermilks contained about $195 \mathrm{mg} / 100 \mathrm{~g}$. The literature data for dairy products to drink, especially of different flavours, are very limited. Kunachowicz and co-authors (2015) estimated the content of $\mathrm{P}$ in kefirs to be $74 \mathrm{mg} / 100 \mathrm{~g}$ while in buttermilks to be $80 \mathrm{mg} / 100 \mathrm{~g}$. Lodi and co-authors (2010) who described "fermented milk beverages" showed an even lower content of P (25-50 mg/100 g). In USDA (2019), only several dairy products to drink described in relation to $\mathrm{P}$ content were found. The content of $\mathrm{P}$ for plain and strawberry kefirs was 96 and $105 \mathrm{mg} / 100 \mathrm{~g}$, respectively (analytical determinations) and for plain buttermilk was $85 \mathrm{mg} / 100 \mathrm{~g}$ (nutrition survey).

An interesting category in our study were flavoured homogenized cheeses. They are very popular in Poland but less popular in Europe or worldwide. They are made from pasteurized and acidified cow milk, unflavoured or flavoured (preferably), and mostly consumed as a dessert. The content of $\mathrm{P}$ in most of the analysed homogenized cheeses ranged from $190-240 \mathrm{mg} / 100 \mathrm{~g}$. Only two products contained significantly lower amounts of P: $165 \mathrm{mg} / 100 \mathrm{~g}$ (vanillastrawberry) and $168 \mathrm{mg} / 100 \mathrm{~g}$ (strawberry-peach) which was comparable to the data published by other Polish authors (138-175 mg/100 g) (Kunachowicz et al. 2015). Especially rich in $\mathrm{P}$ were four products (strawberry, raspberry and two vanilla) delivering 250-280 $\mathrm{mg}$ in $100 \mathrm{~g}$.

It is commonly known that dairy products are a good source of P. In the American diet, 20-30\% of P intake is provided by dairy products (Calvo and Uribarri 2013). The products analysed in our study should be regarded as a good source of this mineral. Their portion $(200 \mathrm{~g})$ delivered from 22 to $79 \%$ of NRV for P. Most of them could have nutrition claims related to P. In the European Union these claims can be added to solid products with the minimal content of $105 \mathrm{mg} / 100 \mathrm{~g}$ (claim "source of") or $210 \mathrm{mg} / 100 \mathrm{~g}$ (claim "high in") and to beverages with the minimal content of $52.5 \mathrm{mg}$ ("source of") or $105 \mathrm{mg}$ in $100 \mathrm{~mL}$ ("high in") (Food Safety Authority of Ireland 2019). On the other hand, the guidance for dietary supplements with $\mathrm{P}$ indicate that products containing $\geq 250 \mathrm{mg}$ of $\mathrm{P}$ per portion should carry the statement "This amount of phosphorus may cause mild stomach upsets in sensitive individuals" (EFSA 2009). As the $\mathrm{P}$ deficiency is occasional in the developed populations, the nutrition claims are rarely presented on labels of food products.

\section{Conclusions}

In this paper, the spectrophotometric molybdenum blue method was adapted to simultaneous $\mathrm{P}$ analysis in many samples using a microplate reader. The method is sensitive, precise, accurate and can be implemented in the routine quantitative analysis of $\mathrm{P}$ content in dairy products. The method was applied for 65 dairy products from different categories and flavours. The content of $\mathrm{P}$ in all analysed yogurts, yogurt drinks, kefirs, buttermilks and homogenized cheeses ranged from $78-277 \mathrm{mg} / 100 \mathrm{~g}$. In general, the lowest content of $\mathrm{P}$ was found in yogurt drinks and kefirs and the highest in buttermilks and homogenized cheeses. The 
presented method that allows a fast and reliable analysis of $\mathrm{P}$, and the results for dozens of dairy products are beneficial from both an analytical and nutritional point of view.

Supplementary Information The online version contains supplementary material available at https://doi.org/10.1007/s00003-021-01329-x.

Funding The research did not receive any funds.

\section{Declarations}

Conflict of interest The authors declare that they have no conflict of interest.

Open Access This article is licensed under a Creative Commons Attribution 4.0 International License, which permits use, sharing, adaptation, distribution and reproduction in any medium or format, as long as you give appropriate credit to the original author(s) and the source, provide a link to the Creative Commons licence, and indicate if changes were made. The images or other third party material in this article are included in the article's Creative Commons licence, unless indicated otherwise in a credit line to the material. If material is not included in the article's Creative Commons licence and your intended use is not permitted by statutory regulation or exceeds the permitted use, you will need to obtain permission directly from the copyright holder. To view a copy of this licence, visit http://creativecommons.org/licenses/by/4.0/.

\section{References}

Adesanwo OO, Ige DV, Thibault L, Flaten D, Akinremi W (2013) Comparison of colorimetric and ICP methods of phosphorus determination in soil extracts. Commun Soil Sci Plant Anal 44:3061-3075

Bergquist J, Turner C (2018) Analytical chemistry for a sustainable society - trends and implications. Anal Bioanal Chem 410:3235-3237

Borgi L (2019) Inclusion of phosphorus in the nutrition facts label. Clin J Am Soc Nephrol 14:139-140

Cade-Menun BJ (2005) Characterizing phosphorus in environmental and agricultural samples by $31 \mathrm{P}$ nuclear magnetic resonance spectroscopy. Talanta 66:359-371

Calvo MS, Uribarri J (2013) Contributions to total phosphorus intake: all sources considered. Semin Dial 26:54-61

Calvo MS, Moshfegh AJ, Tucker KL (2013) Assessing the health impact of phosphorus in the food supply: issues and considerations. Presented in: Advances in Nutrition. April 24, Symposium dietary phosphorus excess: a risk factor in chronic bone, kidney, and cardiovascular disease, Boston, USA, pp 104-113

Coşkun N, Akman S (2005) Direct determination of phosphorus in different food samples by means of solid sampling electrothermal atomic absorption spectrometry using $\mathrm{Pd}+\mathrm{Ca}$ chemical modifier. Spectrochim Acta Part B At Spectrosc 60:415-419

Cozzolino D, Kwiatkowski MJ, Dambergs RG, Cynkar WU, Janik LJ, Skouroumounis G, Gishen M (2008) Analysis of elements in wine using near infrared spectroscopy and partial least squares regression. Talanta 74:711-716

Dušek M, Kvasnička F, Lukaškova L, Kratka J (2003) Isotachophoresis determination of added phosphate in meat products. Meat Sci 65:765-769

EFSA European Food Safety Agency (2009) Scientific opinion on the substantiation of health claims related to phosphorus and function of cell membranes (ID 328), energy-yielding metabolism (ID 329,
373) and maintenance of bone and teeth (ID 324, 327) pursuant to Article 13(1) of Regulation (EC) No 1924/2006. EFSA J 7:1219-1236

European Parliament and Council (2011) Regulation (EU) No 1169/2011 of 25 October 2011 on the provision of food information to consumers, amending Regulations (EC) No 1924/2006 and (EC) No 1925/2006 of the European Parliament and of the Council, and repealing Commission Directive 87/250/EEC, Council Directive 90/496/EEC, Commission Directive 1999/10/ EC, Directive 2000/13/EC of the European Parliament and of the Council, Commission Directives 2002/67/EC and 2008/5/EC and Commission Regulation (EC) No 608/2004

Food Safety Authority of Ireland. Information on nutrition and health claims. August 2019. https://www.fsai.ie/publications_nutrition_ healthclaims/. Accessed 11 Nov 2020

Fuente AM, Montes F, Guerrero G, Juárez M (2003) Total and soluble contents of calcium, magnesium, phosphorus and zinc in yoghurts. Food Chem 80(4):573-578

Fukagawa M, Komaba H, Miyamoto K (2011) Source matters: from phosphorus load to bioavailability. Clin J Am Soc Nephrol $6(2): 239-240$

Güler Z (2007) Levels of 24 minerals in local goat milk, its strained yoghurt and salted yoghurt (tuzlu yogurt). Small Rumin Res $71: 130-137$

Hwang J, Jang HW, Namgung B, Oh M, Kim S, Seo D, Kim SN, Choi Y, Yang JSNMO (2015) Determination of phosphorus in foods by inductively coupled plasma optical emission spectrometry (ICPOES). Food Eng Prog 19:161-166

Institute of Medicine, Food and Nutrition Board (1997) Dietary reference intakes for calcium, phosphorus, magnesium, vitamin $\mathrm{D}$, and fluoride. National Academies Press, Washington

Jastrzębska A (2009) Modifications of spectrophotometric methods for total phosphorus determination in meat samples. Chem Pap 63:47-54

Jastrzębska A, Brudka B, Szymański T, Szłyk E (2003) Determination of phosphorus in food samples by X-ray fluorescence spectrometry and standard spectrophotometric method. Food Chem 83:463-467

Koel M, Kaljurand M (2006) Application of the principles of green chemistry in analytical chemistry. Pure Appl Chem 78:1993-2002

Kunachowicz H, Nadolna I, Przygoda B, Iwanow K (2005) Tabele składu i wartości odżywczej żywności (in Polish), Food composition tables, PZWL, Warsaw, Poland

Kurzawa M, Jastrzębska A, Szłyk E (2009) Application of fluorimetric methods for selected additives determination in food products. Czech J Food Sci 27:S337-S341

Lesniewicz A, Wroz A, Wojcik A, Zyrnicki W (2010) Mineral and nutritional analysis of Polish infant formulas. J Food Compos Anal 23:424-431

Lodi CS, Sassaki KT, Fraiz FC, Delbem ACB, Martinhon CCR (2010) Evaluation of some properties of fermented milk beverages that affect the demineralization of dental enamel. Braz Oral Res 24(1):95-101

Mancini FR, Affret A, Dow C, Balkau B, Clavel-Chapelon F, Bonnet F, Boutron-Ruault MC, Fagerazzi G (2018) High dietary phosphorus intake is associated with an increased risk of type 2 diabetes in the large prospective E3N cohort study. Clin Nutr 37:1625-1630

Murphy J, Riley JR (1962) A modified single solution method for the determination of phosphate in natural water. Anal Chim Acta 27:31-36

Perkin-Elmer (2011) Atomic spectroscopy. A guide to selecting the appropriate technique and system. https://www.perkinelmer.com/ Content/relatedmaterials/brochures/bro_worldleaderaaicpmsic pms.pdf. Accessed 14 Nov 2020

Ruiz-Calero V, Galceran MT (2005) Ion chromatographic separations of phosphorus species: a review. Talanta 66:376-410 
Sekiguchi Y, Matsunaga A, Yamamoto A, Inoue YJ (2000) Analysis of condensed phosphates in food products by ion chromatography with an on-line hydroxide eluent generator. J Chromatogr A 881:639-644

USDA U.S. Department of Agriculture, Agricultural Research Service (2019) FoodData Central, https://fdc.nal.usda.gov/. Accessed 14 Nov 2020

Vallapragada VV, Inti G, Ramulu JS (2011) A validated inductively coupled plasma-optical emission spectrometry (ICP-OES) method to estimate free calcium and phosphorus in in vitro phosphate binding study of eliphos tablets. Am J Anal Chem 2:718-725
Zamberlin Š, Antunac N, Havranek J, Samaržija D (2012) Mineral elements in milk and dairy products. Mljekarstvo 62:111-125

Publisher's Note Springer Nature remains neutral with regard to jurisdictional claims in published maps and institutional affiliations. 